\title{
Niña con síndrome de Down e hipertensión pulmonar
}

\section{Girl with Down syndrome and pulmonary hypertension.}

Carlos Corona-Villalobos, ${ }^{1}$ Eduardo López-Corella ${ }^{2}$

\section{RESUMEN CLÍNICO}

La niña llegó a nuestro Instituto a los 11 meses de edad, referida por dificultad respiratoria y con diagnósticos de síndrome de Down, comunicación interatrial (CIA) tipo ostium secundum y estenosis subglótica. Producto del segundo embarazo, de padres de 25 (madre) y 27 (padre) años. En la historia familiar se refiere síndrome de Down en una tía materna. La paciente nació por cesárea a las 38 semanas por oligohidramnios y sufrimiento fetal, pesó $1560 \mathrm{~g}$, con talla de $41 \mathrm{~cm}$, Apgar de $7 / 8$, sin esfuerzo respiratorio al nacer, hospitalizada 45 días, de los cuales 7 requirió ventilación mecánica. Exhibía un fenotipo Down con facies característica, macroglosia y pliegue palmar único, bilateral, con polidactilia en la mano izquierda. Se auscultó un soplo cardiaco y en el ecocardiograma se detectó una comunicación interatrial de $8 \mathrm{~mm}$, con flujo de izquierda a derecha. Egresó con diagnósticos de síndrome de Down, comunicación interatrial, estenosis pulmonar leve, hipertensión arterial pulmonar moderada y displasia broncopulmonar dependiente de oxígeno.

En los nueve meses siguientes se hospitalizó en cuatro ocasiones, por cuadros neumónicos, reflujo gastroesofágico con broncoaspiración, insuficiencia cardiaca y desnutrición progresiva. Requirió ventilación

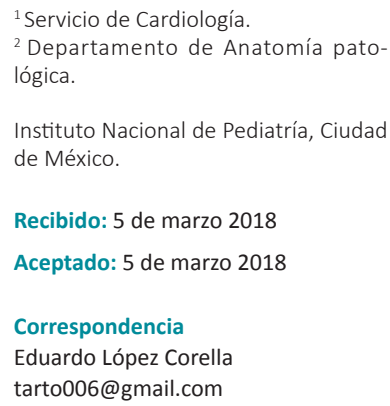
Niña con síndrome de Down e hipertensión pulmonar. Acta Pediatr Mex. 2018;39(3):256-264 
mecánica en varias ocasiones y tuvo estenosis subglótica de 20\% como secuela de éstas. Además, se documentó un bronquio traqueal derecho.

A los 11 meses de edad se incrementó la dificultad respiratoria, por lo que fue referida a este Instituto. Aquí se recibió con dicho padecimiento, caracterizado por aleteo nasal, cianosis y retracción intercostal y supraesternal. Al ingreso tuvo: frecuencia cardiaca de $190 \mathrm{lpm}$, respiratoria de $60 \mathrm{rpm}$ y una tensión arterial de 95-55 mmHg. Los campos pulmonares estaban hipoventilados, con estertores crepitantes en la base derecha y se auscultó un soplo sistólico I/ VI en foco pulmonar.

El hígado se palpó a $3 \mathrm{~cm}$ por debajo del borde costal. La radiografía de tórax con cardiomegalia leve, con índice cardiotorácico (ICT) de 0.6, flujo pulmonar aumentado, atrapamiento aéreo y una consolidación basal derecha. (Figura 1) Su peso fue de $2320 \mathrm{~g}$, con talla de $58 \mathrm{~cm}$ y perímetro cefálico de $36 \mathrm{~cm}$; todos estos por debajo del per-

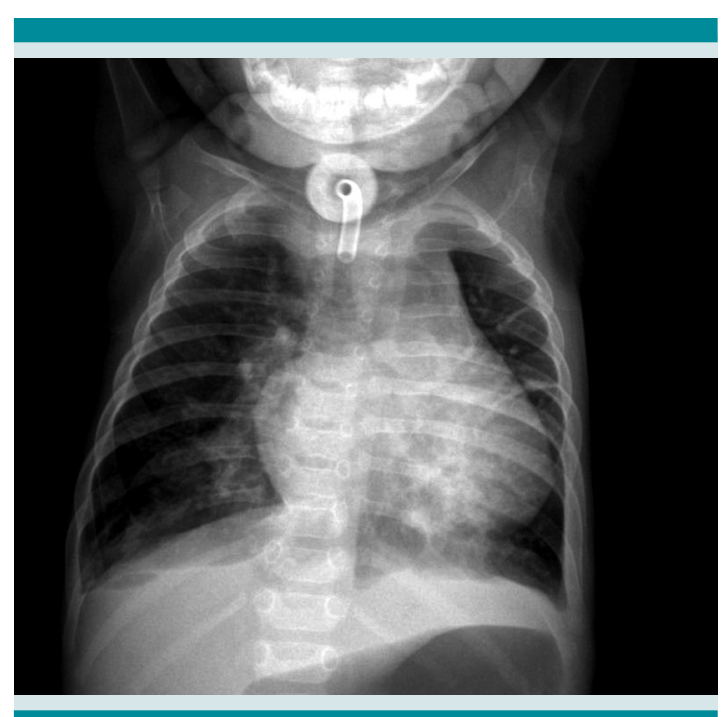

Figura 1. Radiografía de tórax. Flujo pulmonar aumentado, atrapamiento de aire y una consolidación basal derecha. centil 5 de las tablas de referencia de patrones de crecimiento para niños con síndrome de Down.

La intubación era difícil por la estenosis subglótica, al día siguiente se practicó una traqueostomía con la que se lograron disminuir los parámetros de ventilación mecánica. El electrocardiograma fue compatible con crecimiento auricular y ventricular derecho y el ecocardiograma reveló una comunicación interatrial tipo ostium secundum de 7 x 7 mm y datos indirectos de hipertensión arterial pulmonar grave. La hemoglobina era de $8.9 \mathrm{mg} / \mathrm{dL}$, el panel de virus respiratorios por PCR se reportó negativo. La paciente fue dada de alta 10 días después, con oxígeno nocturno, diuréticos (furosemida y espironolactona) y captopril.

En el seguimiento en la consulta externa de Cardiología se comentó que contaba con desaturación periférica y gran hipertensión pulmonar, que no es explicada por la comunicación interatrial a esa edad.

Tres meses después, la paciente reingresó al Servicio de Urgencias por fiebre de $38.5{ }^{\circ} \mathrm{C}$, no controlada con antipiréticos, tos con expectoración, dificultad respiratoria y saturación arterial de oxígeno de 50\%. En la exploración tuvo taquipnea, tiraje intercostal, disociación tóraco-abdominal con Silverman-Anderson de 6, estertores crepitantes finos y sibilancias generalizadas. Se trató, inicialmente, con oxígeno por traqueostomía, nebulizaciones con salbutamol, y metilprednisolona IV por un cuadro de neumonía viral; en la radiografía de tórax se observó cardiomegalia con un ICT de 0.66, incremento del flujo pulmonar, imágenes radioopacas sin broncograma aéreo, por lo que se agregó al tratamiento furosemida intravenosa, con mejoría de los datos de dificultad respiratoria.

Durante su hospitalización en el Servicio de Infectología se realizó una evaluación por parte del Servicio de Gastroenterología que diagnosti- 
có enfermedad por reflujo gastroesofágico hasta el tercio superior, macroglosia, desnutrición grave y talla baja. Se inició tratamiento con rehabilitación orofaríngea cisaprida, omeprazol e incremento del aporte calórico hasta $160 \mathrm{kCal} /$ kg/día, fue dada de alta a los 23 días siguientes.

El seguimiento a cargo de la Clínica de Atención Integral al Niño con Síndrome de Down documentó un retraso psicomotor importante con falta de sostén cefálico, gateo, transferencia de objetos y lenguaje. La Clínica de Neumología le efectuó una broncoscopia en la que se encontró estenosis subglótica fibrosa de $40 \%$, traqueoendobronquitis, hipersecreción de moco y discinesia traqueo-bronquial. No contaba con perfil tiroideo ni con cariotipo. Se cambió la cánula de traqueostomía, sin complicaciones.

Debido a que la paciente empezó nuevamente con fiebre, tos productiva y cianosis perioral que progresó a generalizada, acudió a Urgencias de nuestro Instituto. Ingresó a la sala de choque, sin pulsos, asistolia en el monitor, sin esfuerzo respiratorio, $\mathrm{pCO}_{2}$ de $64.3 \mathrm{mmHg}, \mathrm{HCO}_{3} 8.4$ $\mathrm{mmol} / \mathrm{L}, \mathrm{EB}-27$, saturación $27 \%$, lactato 26.7 $\mathrm{mmol} / \mathrm{L}, \mathrm{Hb} 12.4 \mathrm{mg} / \mathrm{dL}, \mathrm{Na} 136 \mathrm{mmol} / \mathrm{L}, \mathrm{K} 13.3$ $\mathrm{mmol} / \mathrm{L}, \mathrm{Cl} 104 \mathrm{mmol} / \mathrm{L}$, Ca ionizado $5.4 \mathrm{mg} / \mathrm{dL}$ y glucosa no detectable en la gasometría ni en el glucómetro. Tras 27 minutos de maniobras se declaró la defunción.

\section{Diagnóstico clínico final}

- Síndrome de Down

- Cardiopatía congénita tipo comunicación interatrial

- Estenosis subglótica

- Displasia broncopulmonar

\section{Comentario clínico (Dr. Corona Villalobos)}

El síndrome de Down es la alteración cromosómica más frecuente en la raza humana y puede presentarse hasta en 1 de cada 800-1000 naci- mientos. En México, la prevalencia es de 3.73 por cada 10,000 nacimientos. ${ }^{1}$ La alta incidencia de cardiopatías estructurales es bien conocida y alcanza 40 a $60 \%$ de estos niños. La cardiopatía reportada con más frecuencia en el mundo es el defecto de la tabicación atrio-ventricular (canal AV); sin embargo, algunas publicaciones en América Latina, incluyendo nuestro Instituto, reportan mayor frecuencia de comunicación interventricular, comunicación interatrial y persistencia del conducto arterioso. ${ }^{2,3}$ Todas estas cardiopatías son acianógenas (sin desaturación), de flujo pulmonar aumentado y requieren tratamiento médico con anticongestivos (diuréticos) e inhibidores de la enzima convertidora de angiotensina y corrección quirúrgica o, en algunos casos, intervencionista.

El descenso en la saturación arterial de oxígeno en un paciente con síndrome de Down debe analizarse como un dato clínico que no necesariamente está relacionado con la cardiopatía de flujo pulmonar aumentado, ya que existen múltiples factores que pueden propiciarla. Algunos de estos son: 1) obstrucción respiratoria crónica superior secundaria a alteraciones en el macizo facial, macroglosia e hipotonía generalizada, ${ }^{4}$ 2) alteraciones en el crecimiento vascular arteriolar pulmonar, 3) hipoventilación alveolar, ${ }^{5} 4$ ) infecciones respiratorias recurrentes y 5 ) menor número de alvéolos que pueden agravar la enfermedad vascular pulmonar. ${ }^{6}$ Otras alteraciones que deben descartarse son las gastrointestinales (atresia-estenosis duodenal y enfermedad de Hirschsprung), que pueden favorecer el reflujo gastroesofágico y, en casos graves, la microaspiración.

A pesar del abordaje clínico, los niños con síndrome de Down pueden tener alteraciones que sólo se evidencian con el estudio patológico y que no son susceptibles de tratamiento correctivo. 
Consideramos que en este caso hubo múltiples factores que favorecieron la mala evolución clínica y los cambios vasculares en la circulación arterial pulmonar, que en condiciones habituales no suelen presentarse en pacientes con comunicación interatrial sino hasta la cuarta década de la vida.

Finalmente, la desnutrición fue un factor que contribuyó al rápido deterioro de este paciente, por lo que en niños como estos, con múltiples comorbilidades, no debe olvidarse que la base del tratamiento es un plan nutricional muy intenso, donde incluso pueda considerarse la gastrostomía para asegurar los requerimientos calóricos elevados.

\section{Comentario anatomopatológico (Dr. López Corella)}

Esta niña llegó a la autopsia en estado caquéctico, con hipotrofia muscular generalizada; pesaba $4 \mathrm{~kg}$ con una talla de $61 \mathrm{~cm}$. Tenía la facies característica de síndrome de Down con epicanto, aplanamiento del dorso de la nariz, pliegue palmar único en ambas manos y un pulgar supernumerario en la mano izquierda. (Figura 2A)

En el examen interno se encontraban los estigmas del síndrome: en el cerebro se apreciaba hipoplasia de la primera circunvolución temporal en ambos lados y había aplanamiento del polo occipital. (Figura 2B)

Los pacientes con síndrome de Down, portadores de anomalía cromosómica en todas las células de su economía, presentan una diversidad de anomalías, malformaciones y disfunciones en muchos aparatos y sistemas que reflejan un desarrollo de estructuras orgánicas y tisulares que se aleja de la norma. En esta niña la malformación cardiaca, que se discute más adelante, concentró la atención durante su curso
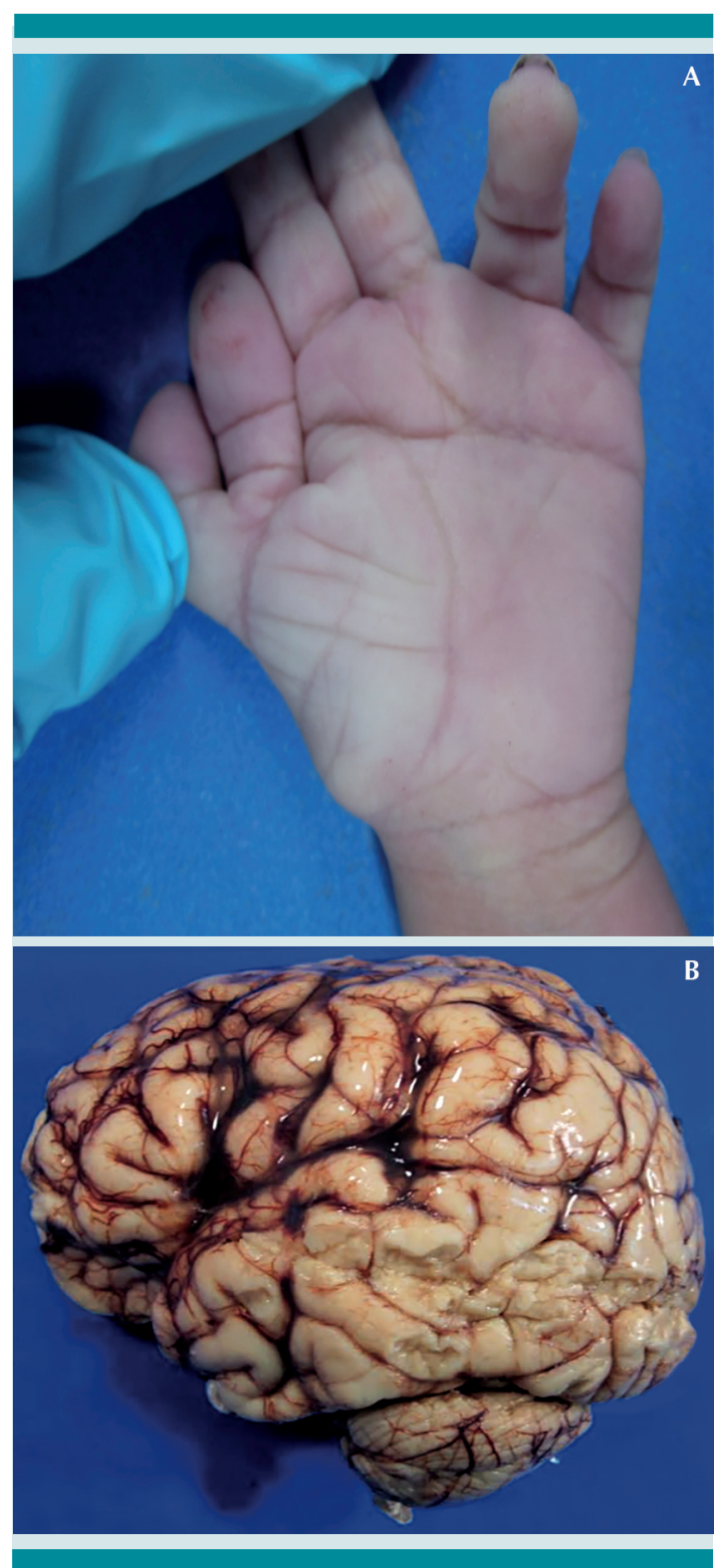

Figura 2. Estigmas macroscópicos de Down. (A) Mano: pliegue palmar único y polidactilia. (B) Cerebro: hipoplasia de la primera circunvolución temporal y aplanamiento del polo occipital.

clínico, pero en la autopsia encontramos alteraciones tisulares menores como una glándula paratiroides intra-tiroidea, no necesariamente anormal pero no habitual, y había en el seno del 
parénquima hepático inclusiones de tejido de la adrenal adyacente, seguramente sin ninguna repercusión clínica. (Figura 3) Un bronquio traqueal, que puede asociarse con el síndrome de Down y que fue identificado en vida, aumenta el riesgo de neumonías recurrentes y cuadros de aspiración, como probablemente sucedió a la paciente. (Figura 4A)

Las malformaciones cardiacas son frecuentes en los niños con síndrome de Down y en nuestro caso tenemos una CIA de tipo ostium secundum, diagnosticada desde el nacimiento, pero que por sí sola no explica la hipertensión pulmonar, como ya se comentó en el curso de la evolución de nuestra paciente. Además, tenía una vena cava superior izquierda persistente que drenaba al seno coronario, el cual se encontraba dilatado pero que tampoco es determinante en el curso clínico. (Figura 5)

Más importante es la reconocida inmadurez pulmonar característica del niño con Down, con una menor población de alvéolos y un retraso en el desarrollo de la vascularidad pulmonar. ${ }^{7}$ (Figura 4B) Esto propicia el desarrollo de una hipertensión pulmonar grave, que fue lo que encontramos en esta niña; en todo el árbol arterial pulmonar se aprecia hipertrofia marcada de la capa muscular con disociación de las fibras elásticas; la microvascultura pulmonar mostraba arteriolización de los capilares intra-acinares con duplicación de la lámina elástica. (Figura 6)

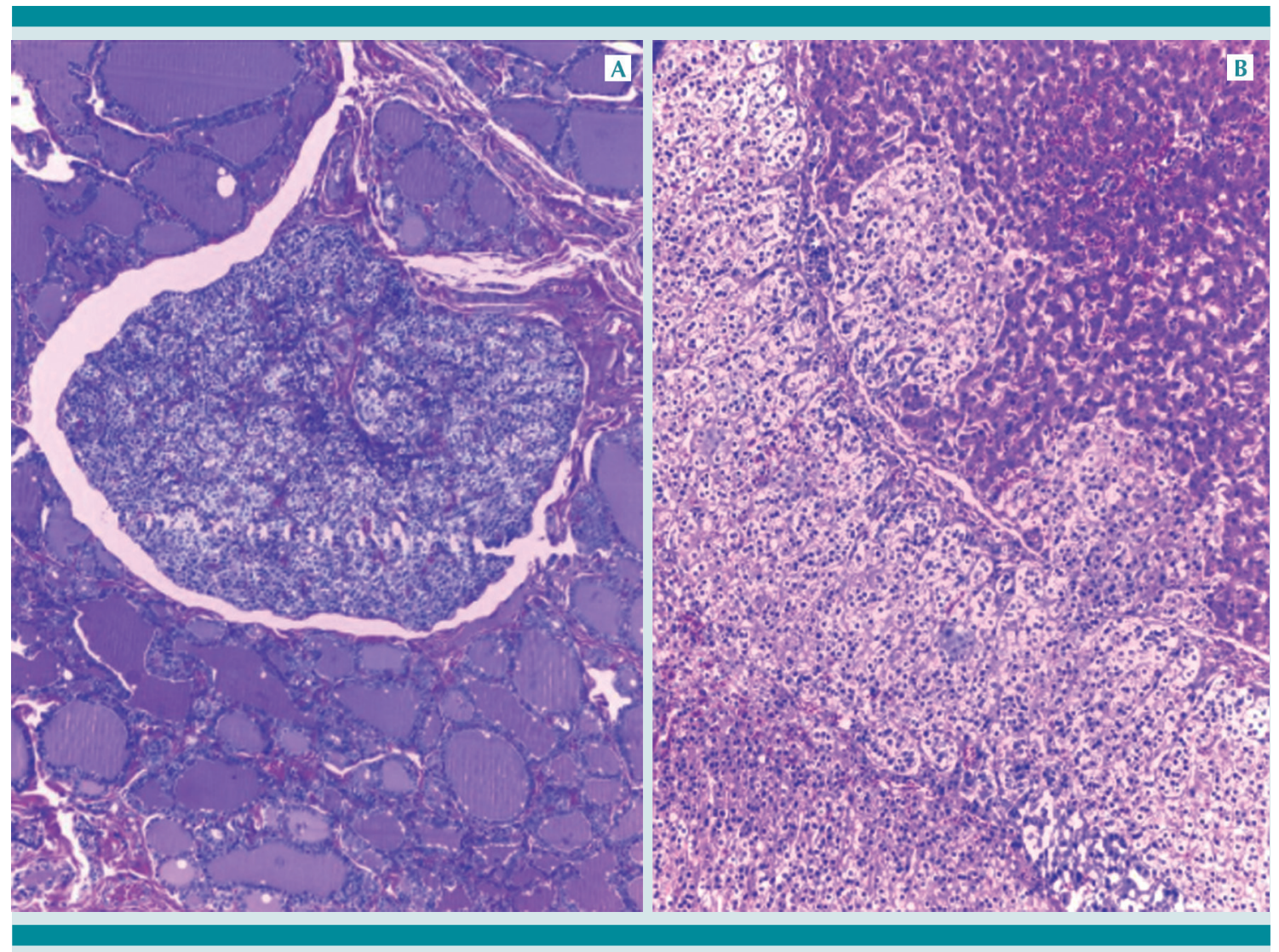

Figura 3. Anomalías tisulares menores en el síndrome de Down. (A) Paratiroides intratiroidea. (B) Tejido adrenal en el hígado. (Hígado arriba a la derecha). 


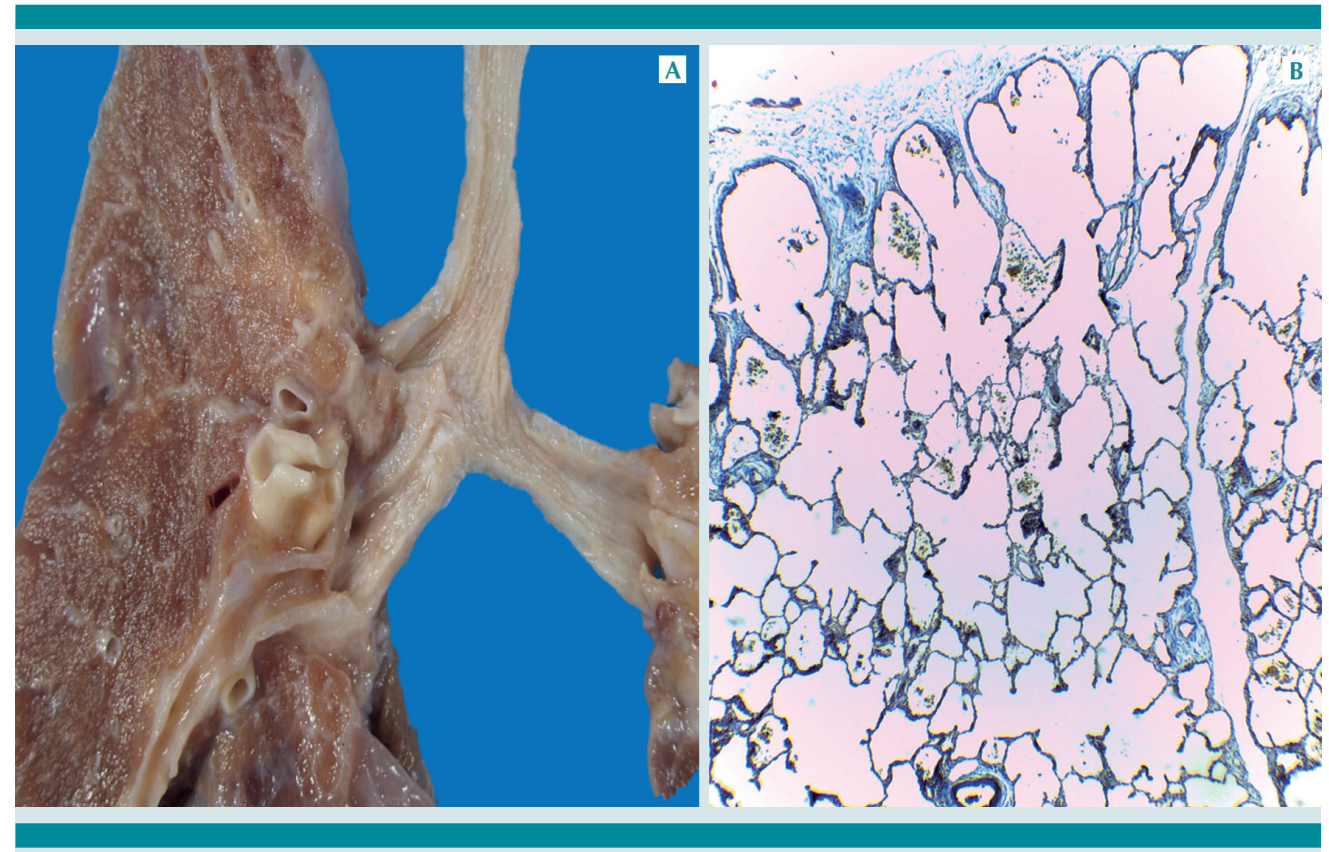

Figura 4. (A) Bronquio traqueal derecho. El bronquio del lóbulo superior derecho sale directamente de la tráquea. (B) Pulmón con poca cantidad de alvéolos, distendidos y con material aspirado.

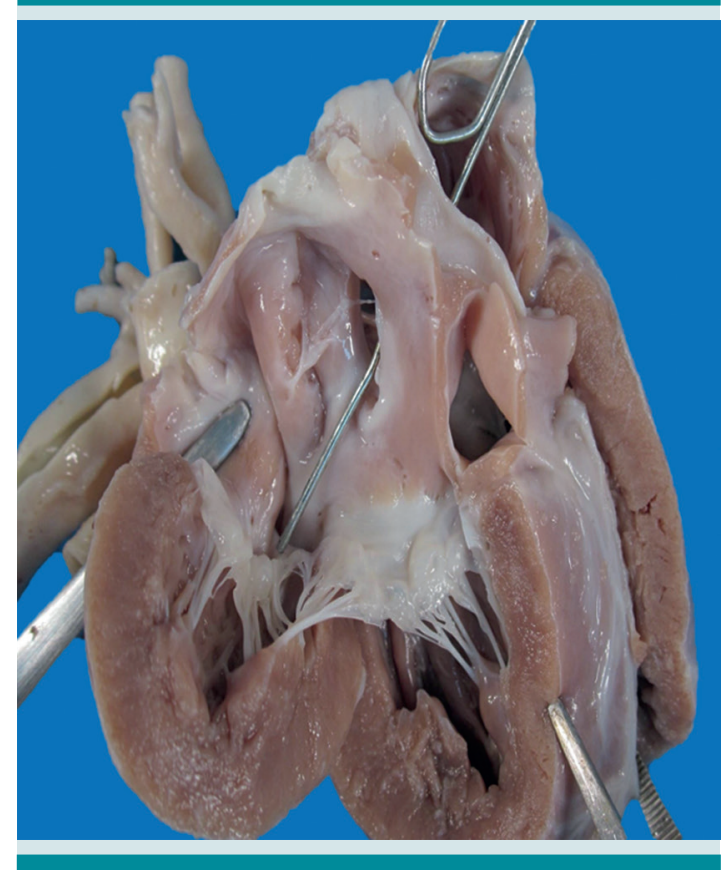

Figura 5. Imagen macroscópica del corazón, que muestra el sitio de la vena cava superior izquierda persistente, que drenaba al seno coronario.
La mayor susceptibilidad a la hipertensión arterial pulmonar es reconocida en el niño con síndrome de Down, sobre todo en residentes a altitudes relativamente altas como el altiplano mexicano, y que se presentan sin asociación necesaria con malformación cardiaca. ${ }^{8}$ La inmadurez alveolar, con pocos alvéolos y distendidos, en un paciente con reflujo gastroesofágico propicia problemas de aspiración; en la paciente encontramos material aspirado en bronquiolos y alvéolos. Probablemente, el bronquio traqueal derecho haya contribuido a problemas de aspiración aunque en la autopsia estos se encontraron en ambos pulmones. El avanzado estado de desnutrición y la propia respuesta inflamatoria débil del paciente con síndrome de Down puede explicar la ausencia de una reacción inflamatoria al material aspirado.

La paciente tuvo una evolución tormentosa, con múltiples hospitalizaciones y con ventilación mecánica repetida; como secuela encontramos en la autopsia una estenosis subglótica cicatrizal 


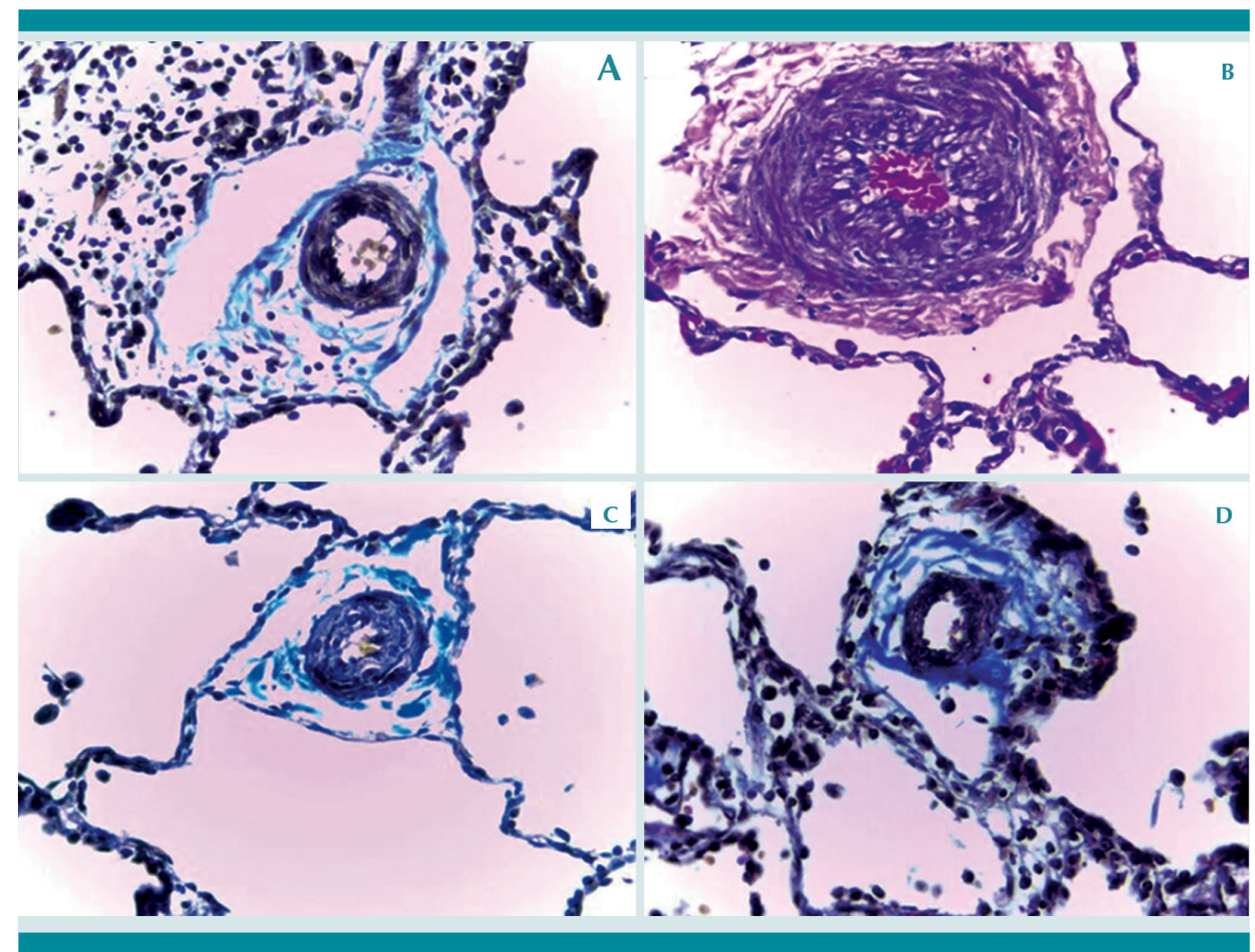

Figura 6. Pulmón. Arterias pequeñas intraacinares engrosadas, con hiperplasia muscular de la media y disociación de fibras elásticas.

importante que seguramente complicó la función ventilatoria y los procedimientos de intubación y que obligó a practicar una traqueostomía poco después de su ingreso con nosotros. (Figura 7)

No explicamos la caquexia. Aunque se sabe que los niños con síndrome de Down tienen problemas de absorción y deficiencias nutricionales diversas, éstas no suelen conducir a estados de desnutrición avanzada. De hecho, los niños en edad escolar tienden más a la obesidad, probablemente por hipoactividad. En la paciente, todos los esfuerzos por nutrirla resultaron infructuosos. La caquexia quizás estuvo más en relación con el estado de hipoxia crónica, resultante de su deficiente desarrollo tisular pulmonar y del daño vascular por la hipertensión pulmonar.
Una asignatura pendiente en el estudio de esta paciente es un análisis genético orientado hacia su anormalidad cromosómica. Es reconocido que la edad materna, mayor de 35 años, es un factor de riesgo para tener un embarazo con trisomía. En esta niña, hija de padres jóvenes, es de sospecharse que su alteración podría no ser la trisomía 21 habitual, presente en alrededor del 95\% de los pacientes con síndrome de Down. Aunque más de la mitad de los nacimientos con este síndrome aparecen en madres jóvenes, esto está sesgado por ser las madres jóvenes el segmento poblacional con mayor fertilidad. A pesar de esto, una pareja joven con un niño con síndrome de Down debe ser objeto de estudios especiales, ya que puede estar dentro del $5 \%$ de nacimientos que no exhiben una trisomía 21 habitual, sino 


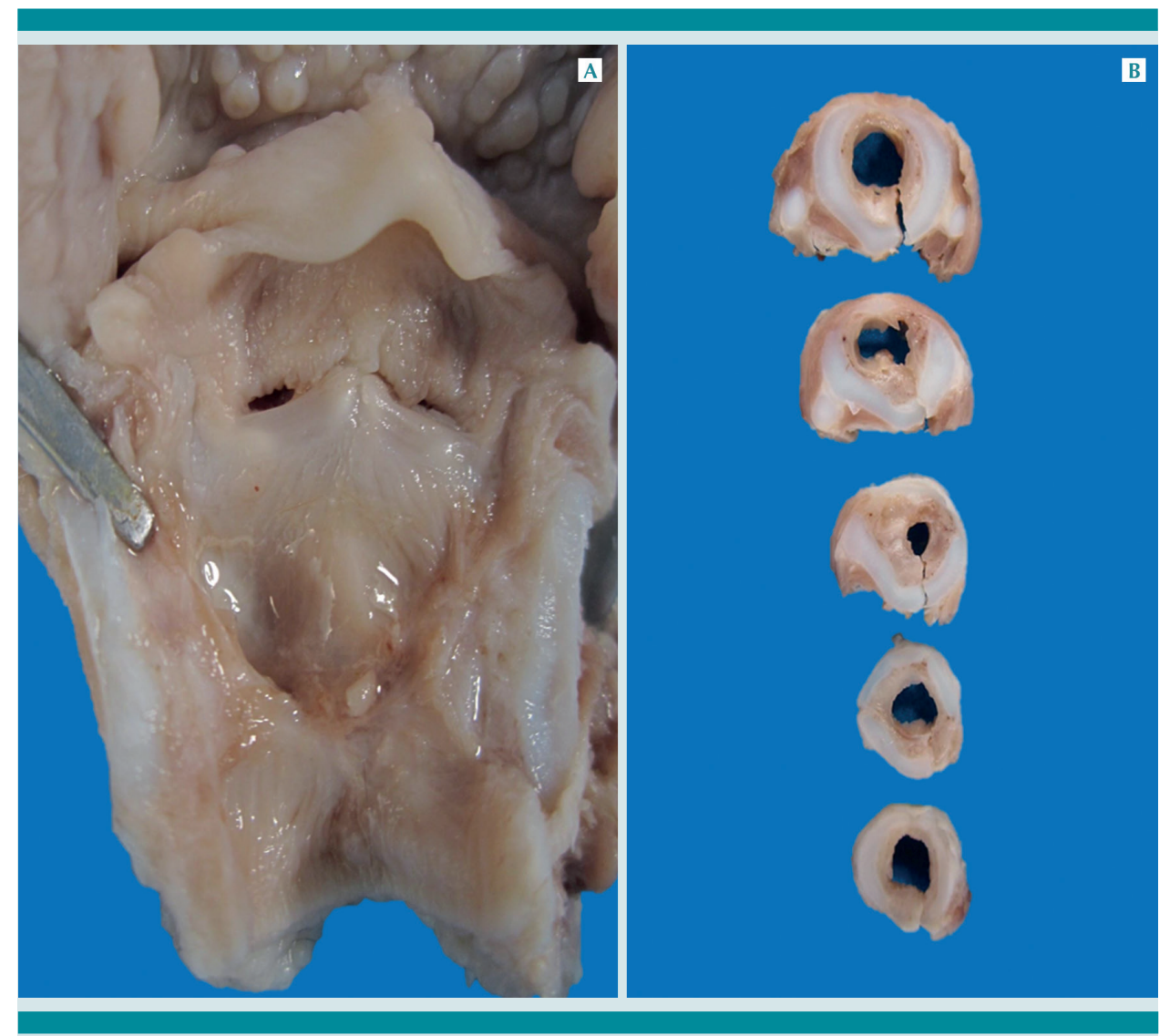

Figura 7. Laringe. Estenosis subglótica cicatrizal.

que pueden tener alguna de las translocaciones descritas en el síndrome y que aumentan el riesgo de recurrencia. Con la trisomía 21 habitual, el riesgo de recurrencia en embarazos ulteriores es del orden de $1 \%$ pero aumenta hasta $5 \%$ en la translocación $14 ; 21$ y hasta $100 \%$ en la $21 ; 21 .{ }^{9}$

\section{Diagnósticos anatómicos principales}

\section{Síndrome de Down}

- Facies Down. Pliegue palmar único bilateral

- Polidactilia en la mano izquierda

- Hipoplasia de primera circunvolución temporal, bilateral
- Inmadurez pulmonar con retraso alveolar

- Arteriopatía hipertensiva pulmonar avanzada

- Material aspirado en bronquiolos y alvéolos Bronquio traqueal derecho

- Anomalías tisulares menores

- (Historia de oligohidramnios)

\section{Cardiopatía congénita}

- Comunicación interauricular amplia, tipo ostium secundum

- Hipertrofia ventricular derecha

- Vena cava superior izquierda persistente con dilatación de seno coronario 


\section{Estenosis subglótica cicatrizal}

\section{Desnutrición avanzada con caquexia}

\section{REFERENCIAS}

1. Sierra-Romero $M$, Navarrete-Hernández $E$, Canún-Serrano S. Prevalencia del síndrome de Down en México utilizando los certificados de nacimiento vivos y de muerte fetal durante el periodo 2008-2011. Bol Med Hosp Infant Mex. 2014: 71: 292-7.

2. De Rubens-Figueroa JJ, del Pozzo B., Pablos JL, y otros. Malformaciones cardíacas en los niños con síndrome de Down. Rev Esp Cardiol. 2003;56: 894-9.

3. Bermúdez BEBV, Medeiros SL, Bermúdez MB. Down syndrome: Prevalence and distribution of congenital heart disease in Brazil. Sao Paulo Med J. 2015;133:521-4.
4. Jacobs IN, Gray RF, Todd NW. Upper airway obstruction in children with Down syndrome. Arch Otolaryngol Head Neck Surg.1996;122:945-50

5. Levine OR, Simpser M. Alveolar hypoventilation and cor pulmonale associated with chronic airway obstruction in infants with Down syndrome. Clin Pediatr (Phila). 1982;21:25-9.

6. Bajar H. Down's syndrome and pulmonary arterial hypertension. PVRI Review. 2009;1:213-9.

7. Espinola-Zavaleta N, Soto ME, Romero-Gonzalez A, y otros. Prevalence of congenital heart disease and pulmonary hypertension in Down's syndrome: an echocardiographic study. J Cardiovasc Ultrasound. 2015;23:72-7.

8. Colvin KL, Yeager ME. What people with Down Syndrome can teach us about cardiopulmonary disease. Eur Respir Rev. 2017:26:160098 doi.org/10.1183/16000617.0098-2016.

9. Del Castillo-Ruiz V, Uranga-Hernández RD, Zafra de la Rosa G. Genética clínica. México: El Manual Moderno, 2012.

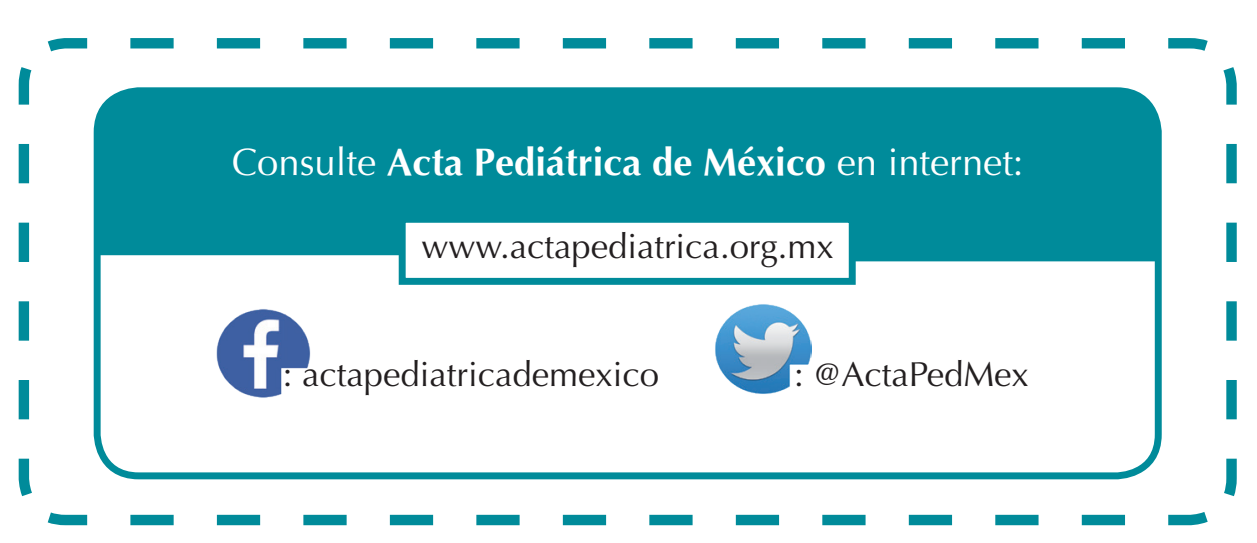

